Disponível em

http://www.anpad.org.br/rac

RAC, Curitiba, v. 14, n. 4

pp. 722-737, Jul./Ago. 2010

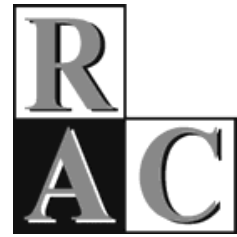

Documentos e Debates:

\title{
Cooperação e Alianças: Perspectivas Teóricas e suas Articulações no Contexto do Pensamento Estratégico
}

\section{Alliances and Cooperation: Theoretical Outlooks in the Realm of Strategic Thought}

* Endereço: Gláucia Maria Vasconcellos Vale PUC Minas: Av. Itaú, 525, Dom Cabral, Belo Horizonte/MG, 30535-012. E-mails: galvale@terra.com.br; galvale@pq.cnpq.br

Copyright (C) 2010 RAC. Todos os direitos, inclusive de tradução, são reservados. É permitido citar parte de artigos sem autorização prévia desde que seja identificada a fonte. 


\title{
RESUMO
}

Prevalece, no campo de estudo das alianças e estratégias colaborativas, um desconhecimento sobre quais são as diferentes perspectivas teóricas aí presentes e como elas podem articular-se entre si, envolvendo questões fundamentais do processo estratégico: a cooperação e o ambiente. O presente artigo, de cunho eminentemente teórico, propõe-se a preencher parte dessa lacuna. Utiliza, como método básico de investigação, uma revisão e análise crítica da literatura internacional e nacional do tema. Emergem sete grandes classes ou perspectivas de abordagens: teorias militares; teoria dos jogos; teoria dos custos de transação; escola do posicionamento e poder de mercado; abordagem das redes sociais; teoria baseada em recursos; abordagem do aprendizado. Observa-se que cada uma delas é detentora de diferentes pressupostos e fundamentos, alguns compatíveis outros incompatíveis entre si. Os resultados, aqui apresentados, permitem, ao pesquisador, uma visão mais integrada e coerente do todo, das interações e convergências aí presentes e de suas possíveis repercussões em termos de pesquisas empíricas.

Palavras-chave: estratégia; teoria; cooperação; alianças; tipologia.

\begin{abstract}
As one surveys the field of cooperative strategies and alliances, some misconceptions are discernible concerning which are the main theoretical frameworks and how they can be articulated among themselves when they focus upon issues such as the strategic process, cooperation and the environment. This article offers a theoretical contribution to this subject. It uses, as a methodological approach, an extensive study and review of the contextual literature. Seven main theoretical outlooks are advanced: military theories; the game theory; the transaction cost theory; the positioning approach; the social networks theory; the resource-based theory; and learning theories. Each one holds a particular set of premises and is derived from specific foundations. Some are compatible with one another, while others are not. The results allow both a more comprehensive view of the whole and an outlook on the possibilities for articulations among the different perspectives and their repercussions on empirical research.
\end{abstract}

Key words: strategy; theory; cooperation; alliance, typology. 


\section{INTRODUÇÃO}

A preocupação mais estruturada e sistemática com o tema das parcerias e alianças empresariais, no contexto do pensamento estratégico, é relativamente recente. E não poderia ser diferente. O próprio campo de conhecimentos sobre estratégica organizacional também o é. Como salientado por Mellahi e Sminia (2009, p. 2), a gestão estratégica "emergiu como um campo de pesquisa acadêmica na década de 1960". Mas apenas nos últimos vinte anos é que essa área de conhecimentos se "institucionalizou em muitos centros acadêmicos de administração” (Mahoney \& McGahan, 2007, p. 93). No entanto, as origens das reflexões sobre cooperação, envolvendo duas ou mais empresas, não são novas. A teoria econômica, ao longo do século XX, voltou sua atenção para alguns mecanismos de cooperação empresarial, a exemplo das coalizões entre firmas, e os seus impactos no funcionamento do mercado (Cohen \& Cybert, 1965). Em que pesem alguns trabalhos esporádicos na área (Pfeffer \& Nowak, 1976), a incorporação da temática da cooperação no conjunto dos grandes temas de pesquisa dos estrategistas organizacionais sobreveio sobretudo nas últimas duas décadas, acompanhando grandes transformações no próprio ambiente de negócios. A globalização, o avanço da microeletrônica e das novas tecnologias de informação passaram a exigir das empresas novas posturas, diferentes formas de inserção no mercado e distintos mecanismos de interação e comunicação. Muitos autores, ao longo do tempo, se vêm referindo a esse fenômeno.

Para Lowendahl e Revang (1998), por exemplo, a grande disseminação de novos conhecimentos e tecnologias vem estimulando a formação de várias modalidades de alianças e parcerias empresariais. Para Lastres e Ferraz (1999), as estratégias colaborativas, desaguando em redes empresariais de todo tipo, representam a mais importante inovação organizacional associada à difusão de um novo paradigma técnico-econômico das tecnologias da informação e da economia da informação e do conhecimento. Para Malerba (2005) decisões estratégicas que envolvem parcerias são contingentes na estrutura industrial e na base de conhecimentos hoje disponíveis para as organizações. Destacam Mintzberg, Ahlstrand e Lampel (2000, p. 188) que, “com a rápida ascensão dos relacionamentos cooperativos, a formação de estratégias deixa os limites exclusivos da organização isolada e torna-se um processo conjunto, para ser desenvolvido com parceiros”. Nesse ambiente em que proliferam diferentes formas de cooperação e alianças empresariais, o acervo de estudos e pesquisas dedicados ao tema se vem ampliando consideravelmente, com contribuições provenientes de diferentes áreas de conhecimentos, incluindo, além da teoria das organizações, economia, sociologia, ciências políticas, marketing etc.

Esse campo de estudos compõe, hoje, um conjunto, ao mesmo tempo, rico e diversificado e, também, disperso e desarticulado. O resultado, como seria de se esperar, é uma multiplicidade de diferentes concepções teóricas e distintas perspectivas de investigações empíricas. Tal fato vem sendo observado, ao longo do tempo, de diferentes maneiras. Contractor e Lorange (1988), dois dos pioneiros nos estudos das estratégias colaborativas de nível internacional, salientam o caráter fragmentado da literatura sobre alianças estratégicas. Osborn e Hagedoorn (1997) observam aí a presença de certo caos. Costa (2005) considera a área uma verdadeira colcha de retalhos. Franco (2007, p. 149) salienta que a bibliografia que faz referência à cooperação empresarial "permanece vasta, complexa e fragmentada”. De fato, prevalece, ainda hoje, no campo de estudos sobre alianças e estratégias colaborativas, um relativo desconhecimento sobre quais são as diferentes perspectivas teóricas e suas interconexões.

O presente artigo, de cunho eminentemente teórico, propõe-se a preencher parte dessa lacuna, ao identificar, no contexto da ampla literatura sobre estratégia, as principais vertentes teóricas que abordam a temática da cooperação e parceria e verificar como elas podem articular-se entre si, no que diz respeito a concepções do processo estratégico: a cooperação e o ambiente. Para viabilizar este trabalho foi utilizado, como método básico de investigação, uma revisão e análise crítica da literatura internacional e nacional sobre o tema. Afloram, nesse contexto, sete grandes perspectivas de abordagens: teorias militares; teoria dos jogos; teoria dos custos de transação; posicionamento e poder de mercado; abordagem das redes sociais; teoria baseada em recursos; abordagem do aprendizado. 
Na primeira parte do artigo são apresentadas as sete categorias ou perspectivas de análises. Observase que houve aí uma preocupação em contextualizar cada uma delas, em identificar alguns autores e obras que pudessem ser considerados representativos e em extrair algumas proposições e concepções teóricas básicas. Na segunda parte é realizada uma análise comparada entre elas, destacando as diferentes visões e concepções do processo estratégico, a cooperação e o ambiente. Finalmente, nas considerações finais, é feita uma avaliação de eventuais compatibilidades - ou incompatibilidades presentes no interior do conjunto analisado e suas possíveis repercussões em termos de pesquisas empíricas.

\section{IDENTIFICAÇÃo E ANÁLISE DAS PERSPECTIVAS TEÓRICAS}

Vários autores apresentam diferentes níveis de contribuições para uma melhor sistematização ou compreensão do tema das estratégias colaborativas, avançando em certas categorias ou tipologias de análises. É o caso, por exemplo, de Volberda (2004) e de Elfring e Volberda, (2001) com o conceito de boundary school; de Koza e Lewin (1998) com uma taxonomia sobre alianças estratégicas; de Preece (2006), que apresenta as três possibilidades de definição de uma aliança estratégica; de Eiriz (2001) que apresenta as várias formas possíveis de que se podem revestir as alianças estratégias; de Kanter (1990) e Child, Faulkner e Tallman (2005), que buscam os fundamentos e tipos possíveis de alianças; de Costa (2005), que registram cinco áreas preferenciais de estudos; de Begni, Pedrozo e Estivalete (2008), que identificam três áreas preferenciais de estudos. Mas o que se observa é que o campo carece, ainda hoje, de visão geral mais integrada, capaz de resgatar, incorporar e interrelacionar proposições hoje dispersas em várias áreas de conhecimentos.

A tentativa de realização de um trabalho desse tipo apresenta alguns desafios. A preocupação que norteou a presente investigação foi a de identificar e avaliar os principais blocos de concepções teóricas que embasam estudos na área, distinguindo, analisando e comparando os fundamentos e pressupostos básicos aí presentes, no que diz respeito ao processo estratégico, à noção da cooperação e à visão do ambiente. Nesse contexto, alguns cuidados tiveram que ser tomados. O primeiro deve-se à natureza do posicionamento da temática da cooperação, no interior tanto de algumas escolas de estratégia, em geral, quanto de alguma área de conhecimento. Tal tema, eventualmente, encontrava-se aí inserido de maneira mais ou menos difusa ou parcialmente escondida. Houve, então, um esforço de maior explicitação. Foi o caso, por exemplo, da abordagem do poder de mercado, cujas bases teóricas se encontram inseridas na escola que Mintzberg et al. (2000) designaram por Posicionamento. Foi o caso, também, da abordagem das redes sociais, extraída do amplo domínio da sociologia econômica e da teoria das redes sociais.

Um segundo tipo de cuidado adveio da necessidade de caracterizar, de maneira mais clara e inequívoca, as linhas divisórias existentes entre as várias perspectivas teóricas. Nota-se, em alguns momentos, que existem algumas sobreposições. É o caso, por exemplo, da teoria baseada em recursos e das teorias de aprendizado. Um terceiro tipo de cuidado adveio do fato de que, na criação de quaisquer categorias de análises, existe sempre o risco de valorizar certos atributos ou fundamentos de um determinado construto teórico-conceitual, em detrimento de outros, de maneira a permitir maior coerência analítica. Buscou-se minimizar isso, recorrendo-se à origem ou ao cerne de cada uma das proposições e concepções teóricas estudadas.

\section{Teorias Militares}

A palavra estratégica origina-se do grego stratêgiká, que significa as táticas ou manobras de um general ou um tratado sobre as técnicas de guerra (Houaiss \& Vilar, 2001). A arte ou ciência da estratégia nasceu de observações, reflexões e proposições sobre os campos de batalha, as manobras militares, os confrontos políticos e as negociações diplomáticas. Quinn (2006) observa que grande parte do conhecimento atual sobre estratégia resultou de uma apropriação, adaptação e atualização de 
idéias, proposições e máximas já observadas por autores clássicos, a exemplo de Zun Tzu, Maquiavel, Von Clausewitz e Foch. Para Quinn (2006), conceitos similares aos utilizados no passado por generais e diplomatas "permeiam as estratégias bem sucedidas - sejam elas governamentais, diplomáticas, militares ou empresariais" (p. 32). O domínio das estratégias militares e diplomáticas sempre foi permeado por intrigas, rivalidades latentes, disputas acirradas, guerras declaradas, negociações e acordos circunstanciais e provisórios.

Nesse contexto destaca-se a temática das coalizões, que constituem alianças temporárias, realizadas por diferentes agentes (indivíduos, empresas, grupos, países etc.) dotados de objetivos muito diferentes entre si. Gambson (1961), ao elaborar a sua teoria da formação de coalizão, menciona, como exemplo extremo de coalizão, o caso de Hitler e Stalin, dois adversários mortais que assinaram, às vésperas da Segunda Guerra Mundial, um Pacto de não agressão (Pacto Ribbentrop-Molotov) pretendendo, cada um deles, ganhar tempo antes do inevitável confronto final. No contexto dos estudos organizacionais, Thompson (1967) é considerado um dos pioneiros a enfocar a formação de coalizões (Hoskisson, Hitt, \& Wan, 1999).

Na coalizão, os atores envolvidos são capazes de atingir objetivos mutuamente excludentes no futuro, por meio de alianças no presente, capazes de garantir, a cada um deles, o atendimento a certos propósitos imediatos. Não raro, no mundo dos negócios, duas ou mais empresas são capazes de se associar, temporariamente, com o propósito, por exemplo, de superar um hiato competitivo circunstancial, obter ou preservar algum tipo de vantagem competitiva ou enfraquecer um concorrente. Preece (2006) recorre a conceito semelhante, quando se preocupa em descrever a estratégia empresarial movida por interesses que ele classifica como de gerar restrições. Nesse caso "dois ou mais parceiros se reúnem para impedir a concorrência ou beneficiar-se do poder combinado de mercado” (Preece, 2006, p. 228)”. Mintzberg (2006), fazendo analogias com estratégias militares, enfatiza as possibilidades de fixação de preços ou de formação de cartéis, entre as possíveis estratégias de colaboração envolvendo rivais.

Dentro dessa perspectiva de análise, o ambiente é vislumbrado como um espaço povoado por ciladas e empecilhos a serem contornados ou superados, por mediação de acordos e parcerias circunstanciais, até mesmo com rivais potenciais ou reais. O estrategista é visto como um ser racional, capaz de identificar as ameaças do ambiente e as manobras de inimigos (rivais) e de forjar alianças e parcerias momentâneas, que poderão ser rompidas no momento oportuno.

\section{Teoria dos Jogos}

A teoria dos jogos, concebida inicialmente por John Von Neumann e Oskar Morgenstern, parte do principio de que existem interdependências estratégicas coletivas, resultantes de ações individuais. Ou seja, determinado ator (indivíduo, empresa, comunidade, país etc.) é dependente das ações e decisões de outros atores com os quais interage direta ou indiretamente (Wagner, 1958). Tais interações podem ser modeladas em jogo, onde cada ação ou iniciativa se encontra condicionada à expectativa de reação que ela desencadeia. Pode-se dizer que as teorias dos jogos (estratégicos) buscam regras de otimização do comportamento social em situações onde os jogadores rivais (empresas) não dominam o conjunto de variáveis que condicionam o resultado final da decisão. Tal abordagem encontrou solo fértil no campo social e empresarial (Andrade \& Dias, 2002; Dixit \& Nalebuff, 2008). Alguns dos jogos dedicam-se à identificação e modelagem de situações em que interdependências estratégicas são capazes de gerar uma dinâmica particular de competição-colaboração entre as empresas.

Destaca-se aí o Dilema dos Prisioneiros, jogo cuja origem remonta à década de 1950. Com Axelrod (1984, 2001) o jogo transformou-se em um dos pilares dos estudos sobre estratégias de cooperação. O autor explorou circunstâncias em que jogadores racionais e dotados de objetivos aparentemente contraditórios são capazes de aprender a colaborar entre si, visando otimizar benefícios mútuos. Para o autor (Axelrod, 1984, p. 2), o problema inicial básico "ocorre quando a busca do autointeresse (individual) gera os piores resultados para todos os envolvidos". Destaca-se, nesse caso, que o pressuposto de equilíbrio geral neoclássico, de maximização do bem-estar coletivo por meio das 
decisões otimizadas de cada ator, falha quando prevalece o nexo do dilema dos prisioneiros. O dilema dos prisioneiros vem mostrar que, em muitos casos, a racionalidade individual neoclássica (associada à busca do autointeresse) pode ser inconsistente, seja com a maximização da própria utilidade individual, seja com a consecução do máximo de bem-estar coletivo. Nessas circunstâncias, os atores envolvidos podem aprender que a colaboração mútua constitui o caminho mais racional a ser seguido. Esse tema vem sendo objeto de inúmeros estudos e pesquisas na literatura sobre estratégia empresarial (Brandenburguer \& Nalebuff, 1996, 1997; Dixit \& Nalebuff, 1993, 2008; Vale, Amâncio, \& Lima, 2006).

No contexto desses estudos, decisões sobre colaboração podem ser vislumbradas como dependentes de fatores associados à natureza do jogador, a eventuais interdependências existentes nos comportamentos dos atores e a circunstâncias ambientais. Incluem-se aí o tipo de posicionamento competitivo perseguido pela empresas; o impacto das externalidades advindas das interações competitivas; a natureza do fluxo de informações, a possibilidade de repetição dos experimentos; a presença de interlocutores confiáveis capazes de iniciar um processo de diálogo e negociação entre as partes; as possíveis sinergias e ganhos decorrentes da cooperação etc.

\section{Poder de Mercado}

A noção de que as empresas recorrem a parcerias e alianças estratégicas com o propósito de ampliar a competitividade, obtendo posições mais fortes no mercado, busca alguns de seus fundamentos na economia industrial. Nesse contexto situa-se Porter (1980, 1885, 1990, 2003) que, utilizando elementos de análise estrutural, elaborou modelos para a análise da estrutura de um setor ou industry. Advém daí o modelo das cinco forças competitivas que modelam a estrutura do setor/ indústria, caracterizando as regras prevalentes de concorrência. O desempenho de uma empresa irá depender dessa estrutura e, também, da posição relativa que a empresa ocupa no setor, que caracteriza a natureza de seu posicionamento e lhe garante o poder de mercado.

Entre os mecanismos que permitem à empresa uma vantagem competitiva diferenciada, situa-se a capacidade de estabelecer parcerias e desenvolver alianças. Tais articulações podem ocorrer no contexto de uma cadeia produtiva (constituindo uma relação empresa - fornecedor), no contexto de um grupo industrial (reunindo empresas associadas a um determinado grupo) ou em aglomerações regionais de empresas (que constituem os clusters produtivos). Diferentes autores apresentam contribuições nessas áreas. Bowersox (1998), por exemplo, em estudo sobre as vantagens da parceria no contexto de uma cadeia de suprimentos, mostra como todos saem ganhando, quando varejistas, fabricantes e empresas de logística se unem. Newman (1978) e Mascarenhas (1989) abordam o tema da afiliação de empresas a grupos estratégicos. Porter (2003) enfoca a temática das aglomerações regionais de empresas. Para o autor (Porter, 1999, p. 100), "as vantagens competitivas duradouras em uma economia globalizada dependem, cada vez mais, de fatores locais”. Aí se incluem o conhecimento, os relacionamentos, a infra-estrutura, a motivação e outros, de cujo conjunto os concorrentes localizados geograficamente mais distantes não teriam como usufruir.

No contexto desses estudos, a colaboração é vislumbrada, em geral, como parte de uma estratégia visando ao melhor posicionamento de uma empresa ou de grupos de empresas no mercado, tendo em vista a estrutura do setor. O poder de mercado pode advir de decisões empresariais, envolvendo, por exemplo, a parceria entre diferentes empresas situadas em posições distintas da cadeia produtiva, a afiliação a certos grupos empresariais ou a inserção em certas aglomerações produtivas regionais. Caberia ao estrategista estar atento ao ambiente de negócios, calibrar a capacidade de competição de sua empresa com as possibilidades de colaboração, adotando estratégias que permitiriam diferenciar sua empresa das demais. 


\section{Teoria dos Custos de Transação}

A teoria dos custos de transação (Williamson, 1975, 2005), inserida na confluência das vertentes econômicas neoclássica e institucional e inspirada em proposições de Coase (1937) e Simon (1965), dedica-se ao estudo do comportamento organizacional nas interfaces existentes entre a hierarquia e o mercado. Hierarquia e mercado representam casos polares de organização da atividade econômica. Entre eles situam-se as chamadas formas híbridas, onde se inserem as parcerias empresariais. Para Williamson (1975) sempre que ocorre uma transferência de um determinado bem através de uma interface tecnologicamente divisível existem custos de transação. Custos de transação seriam aqueles associados à gestão de sistemas produtivos. Tais custos, segundo o autor, seriam derivados de dois pressupostos básicos: a noção de racionalidade limitada do tomador de decisão (ou seja, a incapacidade humana de prever, no momento da negociação, tudo o que poderá ocorrer durante a vigência de um contrato) e a existência de comportamento interesseiro por parte dos envolvidos na transação (possibilidade de uso de assimetrias de informações em benefício próprio). As empresas, pressionadas a tomar decisões entre produzir internamente determinado bem ou produto (governança baseada em hierarquia) ou adquiri-lo no mercado (governança baseada no mercado) podem investir em uma alternativa intermediária, desenvolvendo, por exemplo, parcerias com fornecedores (formas híbridas de governança).

A escolha da melhor alternativa a ser adotada pela empresa (se vai produzir, se vai comprar no mercado ou se vai desenvolver parceria com algum fornecedor) dependerá de um conjunto de fatores associados às características e condições da transação a ser efetuada, com impacto nos custos de transação. Incluem-se, entre tais fatores, a especificidade dos ativos envolvidos na transação, a frequência das transações e os riscos - presentes ou futuros - aí presentes as incertezas associadas à dinâmica do ambiente de negócios. Em condições em que os custos de transação - no presente e no futuro - associados à realização de parcerias forem considerados menores, a empresa poderá optar por uma associação com um ou mais fornecedores. Essa teoria vem sendo muito utilizada na área de estratégia, em particular em estudos que envolvem a cooperação empresarial no contexto de uma cadeia de suprimentos (Arbage \& Balestrin, 2007; Bradach \& Eccles, 1989; King, 2007; Parkhe, 1993).

Nesse contexto, as empresas são vislumbradas como atores zelosos de seus auto-interesses, mas dotados de racionalidade limitada, com dificuldades de processar todas as informações necessárias e de assumir, sozinhas, riscos associados a eventuais mudanças no ambiente. Em certos contextos são, então, obrigadas a buscar alianças e parcerias externas.

\section{Teoria das Redes Sociais}

Na origem dessas reflexões situa-se Granovetter (1973, 1985), em particular com suas proposições sobre imersão ou embeddedness, ou seja, a noção de que as "transações econômicas de todo tipo se encontram repletas de conexões sociais” (Granovetter, 1985, p. 63). Para o autor, o "mercado anônimo do modelo neoclássico é, virtualmente, não inexistente na vida econômica". Nesse sentido, não seria possível uma análise do fenômeno econômico e das transações mercantis, abstraindo-se de suas raízes sociais. É comum, no mundo dos negócios, um amigo tornar-se parceiro. Da mesma maneira, relações comerciais repetitivas podem ensejar o nascimento da confiança e da amizade. É fundamental conhecer a lógica e a natureza das imersões dos atores (indivíduos ou empresas) nas redes de relacionamentos e nas estruturas sociais. Apenas assim seria possível uma compreensão plena da dinâmica das transações mercantis e das instituições econômicas. Granovetter e McGuirre (1998), em um estudo clássico sobre o nascimento da indústria de eletricidade nos Estados Unidos, mostram como as decisões estratégicas iniciais - incluindo a busca por aliados - que acabaram por forjar a estrutura do setor elétrico no país, foram condicionadas por circunstâncias sociais e relações pessoais. Observase, nesse contexto, que iniciativas empresariais são circunstanciais e dependentes das redes sociais, onde as empresas e seus tomadores de decisão se encontram imersos. Concepções aí geradas vêm 
exercendo impacto nos estudos sobre estratégia e competitividade empresarial (Burt, 1992; Gulati, Nohria, \& Zaheer, 2000; Vale, 2007)

Isso significa que para analisar a lógica das estratégias e alianças empresariais existe necessidade de conhecer, também, a natureza das relações sociais aí presentes. A capacidade de forjar alianças e parcerias encontra-se condicionada a vinculações sociais dos atores envolvidos. Os estudos nessa área incorporam diferentes reflexões. Visam analisar, por exemplo, como ocorrem as interconexões das relações sociais com as empresariais e em que medida uma condiciona ou incrementa a outra e a própria estratégia empresarial (Cross, Borgatti, \& Parker, 2002; Gulati et al., 2000); se o posicionamento competitivo de um ator (a exemplo de uma empresa) no mercado pode ser condicionado ou explicado por sua posição no contexto de uma rede de relações sociais (Burt, 1992); como as alianças estratégicas se encontram imersas no portfolio adaptativo da empresa e nas práticas adaptativas da indústria (Koza \& Lewin, 1998); se as redes sociais presentes em uma organização, ao promoverem a colaboração e a integração entre seus membros, incrementariam decisões estratégicas (Cross et al., 2002).

Tal abordagem contraria pressupostos de que empresas são atores movidos exclusivamente por uma lógica de racionalidade instrumental, capazes de perseguir as melhores alternativas oferecidas pelo mercado. Na verdade, a estratégia adotada é resultante da influência e dos condicionantes gerados pelas estruturas sociais. Prevalece a noção de que o ambiente é composto por uma multiplicidade de redes, onde atuam e interagem atores (individuais e/ou coletivos) que se encontram imersos em diferentes estruturas sociais que, por sua vez, influenciam a natureza das estratégias que são capazes de conceber e implementar. Nesse contexto, as possibilidades estratégicas surgem como resultantes de uma interação dinâmica das redes sociais com os interesses pessoais e empresariais.

\section{Teoria Baseada em Recursos}

Segundo Wernerfelt (1997), a teoria baseada em recursos representa um quebra-cabeça em plena construção. Para Haugstad (1999) essa teoria reuniria vários tópicos associados mas distintos, incluindo: (i) visão baseada em recursos, onde se destacam autores como Grant e Peteraf; (ii) competências essenciais, com Prahalad e Hamel;. (iii) capacidades dinâmicas, com autores como Teece e Pisano. Inserem-se, nesse conjunto, diferentes tipos de reflexões e proposições (Penrose, 1997; Peteraf, 1997; Prahalad \& Hamel, 1997; Teece, 1997; Wernerfelt, 1997). Ao longo do desenvolvimento dessa abordagem, ocorreu uma mudança e ampliação no conceito e na natureza dos recursos considerados estratégicos. Por um lado, tal fato levou a visão estática para uma visão mais dinâmica de recursos e, por outro, de uma ênfase em recursos materiais para uma enorme variedade de recursos de natureza intangível, valorizando-se as competências e capacidades dinâmicas (Lockett, Thompson, \& Morgenstern, 2009).

Para Ambrosini e Bowman (2009) a perspectiva da capacidade dinâmica, que ampliou a visão baseada em recurso, vem, desde a década de 1990, avançando consideravelmente. Destacam os autores que a literatura na área mostra como as alianças podem, de fato, ser vislumbradas como um tipo específico de capacidade dinâmica, à medida que possibilitam a renovação e a reconfiguração dos recursos empresariais. A temática da cooperação vem sendo abordada de diferentes maneiras por distintos autores. Combs e Ketchen (1999), por exemplo, buscam associar a cooperação com desempenhos empresariais. Barney (2002) destaca a importância da combinação de recursos complementares resultantes da associação entre diferentes empresas. Hamel, Doz e Prahajlad (1989) enfatizam as vantagens da colaboração, envolvendo os próprios potenciais concorrentes.

No cerne desses estudos existe o pressuposto de que a cooperação que envolve diferentes empresas cada uma delas dotada de um conjunto específico de habilidades e recursos - é capaz de distingui-las no mercado. A parceria é aí vislumbrada como recurso estratégico fundamental para a sobrevivência e o crescimento das empresas, em ambiente caracterizado por crescente disputa e diferenciação. Salienta-se que algumas concepções presentes nessa abordagem - em particular associadas às capacidades dinâmicas - apresentam grande convergência com proposições voltadas para o 
conhecimento e o aprendizado organizacional. Alguns autores, a exemplo de Hoskisson, Hitt e Wan (1999) chegam a inserir a visão baseada em conhecimento no contexto da visão baseada em recursos. Já, para Haugstad (1999), uma ponte entre a teoria baseada em recursos e as teorias do aprendizado é oferecida por alguns autores que analisam o valor estratégico do aprendizado organizacional.

\section{Teorias Voltadas para o Aprendizado}

Para muitos autores, a força indutora da competitividade empresarial sustentável repousa na capacidade de aprendizado, mudança e evolução da empresa. Buscam mostrar, então, como tal processo ocorre por meio de interações contínuas e dinâmicas entre diferentes agentes (pessoas/ empresas). Como já salientado por Polanyi (1958), a transmissão do conhecimento exige mais que simples palavras. Itami e Roehl (1987) enfatizam a crescente importância dos recursos intangíveis, baseados no conhecimento, no mundo dos negócios. Para Nonaka (1994) e Nonaka e Takeushi (1997) o conhecimento inclui importante dimensão tácita - formada por insights, intuições e pressentimentos. Esse tipo de conhecimento, fundamental no mundo de hoje, pode ser repassado e transmitido a terceiros por mediação do contato pessoal e do compartilhamento no dia a dia. Nesse contexto, as alianças e parcerias empresariais, ao promoverem o aprendizado organizacional interativo, adquirem papel chave.

Diferentes autores aí se situam. Kogut e Zander (1992), por exemplo, enfatizam a importância da complementaridade de conhecimentos no processo de mudança tecnológica. Inkpen (2006), ao analisar como se dá a criação de conhecimentos em alianças estratégicas (envolvendo 40 jointventures formadas por empresas japonesas e americanas) salienta a natureza dinâmica do processo de aprendizado e a importância do conhecimento, resultante de interações de diferentes níveis organizacionais. Larsson, Bentssson, Henriksson e Sparks (1998) especificam os diferentes níveis de estratégias colaborativas, definidos a partir da capacidade de implementação de aprendizado coletivo. Hamel (1991) destaca a busca da competência organizacional por meio do aprendizado, ao estudar alianças internacionais. Kale, Singh e Perlmutter (2000) enfatizam o interesse pela busca do conhecimento e de novas capacidades organizacionais em certas alianças estratégicas.

A riqueza e a variedade de reflexões e proposições podem ser consideradas uma das caracteríticas dessa vertente teórica que, em sua essência, destaca o papel das interações e parcerias dos diferentes atores/empresas, como fonte de geração de novos conhecimentos, fundamental para a competitividade. A cooperação permite deflagrar um processo de troca, adaptação e evolução das empresas no mundo caracterizado por crescente complexidade e rápida mudança tecnológica.

\section{Sintetizando e Comparando as Perspectivas Teóricas}

A Tabela 1 apresenta uma síntese dos principais fundamentos associados ao processo estratégico, à noção de cooperação e parceria e à percepção do ambiente. Pode-se observar, a partir daí, que cada uma das diferentes perspectivas teóricas analisadas é detentora de um conjunto específico de premissas e concepções. 
Tabela 1

\section{Alianças e Estratégias Colaborativas: Perspectivas Teóricas e Fundamentos sobre o Processo Estratégico, a Cooperação e o Ambiente}

\begin{tabular}{|c|c|c|c|}
\hline Base teórica & Processo estratégico & Cooperação e parceria & Visão do ambiente \\
\hline $\begin{array}{l}\text { 1. Teorias Militares: } \\
\text { heranças militares. }\end{array}$ & $\begin{array}{l}\text { Estratégia no contexto de } \\
\text { necessidade de confrontos, } \\
\text { coalizões para defesa de } \\
\text { interesses individuais. }\end{array}$ & $\begin{array}{l}\text { Busca de coalizão como } \\
\text { forma de superação de } \\
\text { limitações e garantia/ } \\
\text { ampliação de recursos } \\
\text { estratégicos }\end{array}$ & $\begin{array}{l}\text { Ambiente hostil, composto } \\
\text { por inimigos naturais e } \\
\text { aliados circunstanciais }\end{array}$ \\
\hline $\begin{array}{l}\text { 2. Teoria dos jogos: } \\
\text { jogos evolucionários } \\
\text { estratégicos }\end{array}$ & $\begin{array}{l}\text { Interdependência nos } \\
\text { comportamentos } \\
\text { estratégicos de potenciais } \\
\text { rivais }\end{array}$ & $\begin{array}{l}\text { Parceria resultante de } \\
\text { experimentação e } \\
\text { aprendizado, evitando } \\
\text { dilema dos prisioneiros e } \\
\text { permitindo otimizar } \\
\text { benefícios mútuos. }\end{array}$ & $\begin{array}{l}\text { Ambiente competitivo onde } \\
\text { atores racionais, capazes de } \\
\text { aprender, buscam otimizar } \\
\text { ganhos }\end{array}$ \\
\hline $\begin{array}{l}\text { 3.Poder de mercado: } \\
\text { posicionamento no } \\
\text { mercado }\end{array}$ & $\begin{array}{l}\text { Estratégia visando melhor } \\
\text { posicionamento de uma } \\
\text { empresa e maior poder de } \\
\text { mercado }\end{array}$ & $\begin{array}{l}\text { Parcerias, no contexto de } \\
\text { uma cadeia produtiva, um } \\
\text { grupo empresarial ou } \\
\text { região, como forma de } \\
\text { incrementar o poder de } \\
\text { mercado de uma empresa }\end{array}$ & $\begin{array}{l}\text { Ambiente competitivo onde } \\
\text { empresa necessita } \\
\text { posicionar-se de maneira } \\
\text { diferenciada. }\end{array}$ \\
\hline $\begin{array}{l}\text { 4.Teoria dos custos } \\
\text { de transação: formas } \\
\text { de governança e } \\
\text { custos de transação }\end{array}$ & $\begin{array}{l}\text { Estratégia derivada da } \\
\text { preocupação com custos de } \\
\text { transação em contexto de } \\
\text { racionalidade limitada e } \\
\text { comportamento } \\
\text { interesseiro. }\end{array}$ & $\begin{array}{l}\text { O recurso às parcerias } \\
\text { como estratégia de redução } \\
\text { dos custos de transação. }\end{array}$ & $\begin{array}{l}\text { Ambiente instável e } \\
\text { turbulento, onde empresas } \\
\text { aliadas buscam reduzir } \\
\text { riscos provenientes de } \\
\text { incertezas e mudanças. }\end{array}$ \\
\hline $\begin{array}{l}\text { 5. Teoria das redes } \\
\text { sociais: as dimensões } \\
\text { sociais das } \\
\text { iniciativas } \\
\text { empresariais }\end{array}$ & $\begin{array}{l}\text { Estratégia resultante de } \\
\text { interações entre relações } \\
\text { sociais e interesses } \\
\text { empresariais }\end{array}$ & $\begin{array}{l}\text { O lado invisível das } \\
\text { alianças e estratégias } \\
\text { empresariais, } \\
\text { condicionadas e } \\
\text { influenciadas pela lógica } \\
\text { das redes sociais }\end{array}$ & $\begin{array}{l}\text { Ambiente formado por } \\
\text { proliferação de redes } \\
\text { sociais e empresariais } \\
\text { interconectadas, que } \\
\text { condicionam oportunidades } \\
\text { individuais e coletivas }\end{array}$ \\
\hline $\begin{array}{l}\text { 6. Teoria baseada em } \\
\text { recursos: } \\
\text { especificidade dos } \\
\text { recursos estratégicos }\end{array}$ & $\begin{array}{l}\text { Estratégia enfocando } \\
\text { utilização/desenvolvimento } \\
\text { de recursos, habilidades e } \\
\text { capacidades internas }\end{array}$ & $\begin{array}{l}\text { O papel das interações e a } \\
\text { visão das alianças entre as } \\
\text { capacidades dinâmicas, } \\
\text { capazes de permitir a } \\
\text { renovação de outros } \\
\text { recursos empresariais }\end{array}$ & $\begin{array}{l}\text { Ambiente com alto grau de } \\
\text { diferenciação, vislumbrado } \\
\text { como plataforma de } \\
\text { oportunidades p/ criação e } \\
\text { desenvolvimento de novos } \\
\text { recursos e capacidades }\end{array}$ \\
\hline $\begin{array}{l}\text { 7. Teorias do } \\
\text { aprendizado: ênfase } \\
\text { no aprendizado } \\
\text { interativo }\end{array}$ & $\begin{array}{l}\text { Associação entre } \\
\text { estratégias, competências } \\
\text { organizacionais e } \\
\text { capacidade de aprendizado }\end{array}$ & $\begin{array}{l}\text { A importância da interação } \\
\text { e do compartilhamento de } \\
\text { conhecimentos entre } \\
\text { empresas na } \\
\text { competitividade } \\
\text { empresarial }\end{array}$ & $\begin{array}{l}\text { Ambiente competitivo e } \\
\text { dinâmico, exigindo } \\
\text { compartilhamento de } \\
\text { informaçoes/ } \\
\text { conhecimentos entre } \\
\text { empresas }\end{array}$ \\
\hline
\end{tabular}

Nota. Fonte: elaborado pelos autores

No contexto das teorias militares, o processo estratégico é vislumbrado como um espaço de conflitos, confrontos e negociações, onde são construídas alianças circunstanciais e onde diferentes atores interagem com o propósito de defender ou consolidar posições ou conquistar novos recursos e espaços de mercado. No contexto da teoria dos jogos, a estratégia envolve um processo dinâmico de interação de potenciais rivais, dotados de racionalidade e com capacidade de aprender a colaborar, 
visando a um ganho total maior. Os pressupostos de racionalidade limitada e de comportamento oportunístico fundamentam o processo no âmbito da teoria dos custos de transação, onde a cooperação é a estratégia escolhida, quando for a de menor custo. No outro extremo - afastando-se de pressupostos de racionalidade e de oportunismo presentes na teoria dos custos de transação - situa-se a teoria das redes sociais, que considera que o processo estratégico pode ser condicionado e afetado pelas redes sociais, onde os atores se encontram imersos. Já no caso das teorias voltadas para o poder de mercado, a estratégia é resultante de processo de posicionamento da empresa, onde a avaliação externa da estrutura do setor possui papel preponderante. Tal caso destoa do observado na teoria baseada em recursos, que enfatiza, no processo estratégico, sobretudo a importância dos recursos e das capacidades dinâmicas internas da empresa. Já as teorias do aprendizado distinguem, nos processos estratégicos, a dinâmica de aprendizado via interação e cooperação.

Existem diferenças acentuadas entre as distintas vertentes teóricas na forma de abordar a temática da cooperação, aliança e parceria. No caso das teorias militares, a noção de cooperação perpassa pela formação de alianças circunstanciais e provisórias, utilizadas como mecanismos de superação de deficiências ou de conquista de espaços estratégicos. No caso da teoria dos jogos, em particular no dilema dos prisioneiros, a cooperação resulta da possibilidade de experimentação e da capacidade de aprendizado da empresa, que chega a compreender que é possível, em alguns casos, otimizar benefícios mútuos. Nas teorias do poder de mercado, destaca-se a importância das parcerias, como forma de melhorar o posicionamento e ampliar o poder de mercado das empresas. Na teoria dos custos de transação, o recurso às parcerias apresenta-se como alternativa para redução dos custos de transação. Já a teoria das redes sociais enfoca o lado invisível das alianças e estratégias empresariais e o impacto das redes sociais nesse contexto. A teoria baseada em recurso enfatiza, entre os recursos estratégicos das empresas, a capacidade de cooperar com parceiros. Por sua vez, as teorias do aprendizado enfatizam a importância do compartilhamento de informações e conhecimentos entre diferentes parceiros no processo de evolução empresarial.

É possível observar que se encontra presente, como elemento saliente em todas as abordagens, uma grande preocupação com a dimensão do ambiente. Essa, no entanto, manifesta-se de formas distintas em cada uma delas. No caso das teorias militares prevalece o pressuposto de hostilidade ambiental e a noção de ambiente composto por inimigos naturais e aliados circunstanciais. Na teoria dos jogos destaca-se a presença de ambiente competitivo, povoado por atores interconectados, com capacidade de aprender e interessados em otimizar seus ganhos. Nas teorias sobre poder de mercado prevalece a noção de um ambiente competitivo, onde a empresa necessita articular-se para melhor posicionar-se em face da existência de forças competitivas. A teoria dos custos de transação, por sua vez, vislumbra a presença de ambiente instável e turbulento, onde empresas aliadas buscam reduzir custos e riscos provenientes de mudanças e incertezas. No contexto da teoria das redes sociais o ambiente é representado por uma proliferação e sobreposição de redes, que formam as estruturas sociais e condicionam as oportunidades individuais e coletivas. Na teoria baseada em recursos o ambiente é vislumbrado como plataforma de oportunidades para a criação e o desenvolvimento coletivo de novos recursos e capacidades. Finalmente, nas teorias do aprendizado, prevalece a noção de ambiente hipercompetitivo e dinâmico, exigindo grande capacidade de compartilhamento de informações e conhecimentos entre diferentes agentes/empresas.

\section{CONSIDERAÇÕES Finais: RefleXõES SOBRE COMPATIBILIDADES E ENCADEAMENTOS EMPÍRICOS}

Comparando-se as sete vertentes de análise é possível identificar maiores ou menores sintonias entre elas. Algumas teorias são incompatíveis entre si e dificilmente poderiam ser conjugadas em certas investigações empíricas. É o caso, por exemplo, da teoria das redes sociais com a teoria dos custos de transação. Os pressupostos associados à noção de comportamento interesseiro, presente nessa última, seriam, à primeira vista, incompatíveis com proposições presentes na primeira, que incorporam 0 
princípio da confiança recíproca como o cimento de muitas relações sociais. A teoria das redes sociais também apresenta certas incompatibilidades com abordagens presentes na teoria dos jogos. No outro extremo, existem teorias que apresentam alta compatibilidade entre si. É caso, por exemplo, da teoria baseada em recursos e das teorias do aprendizado. Mas diferentes enfoques teóricos podem engendrar distintos tipos de abordagens empíricas.

No bojo das teorias militares, podem situar-se de maneira conveniente, análises de estratégias empresariais agressivas baseadas em parcerias circunstanciais ou momentâneas, implementadas por empresas líderes, na batalha pela conquista de maiores fatias de mercado. No contexto da teoria dos jogos - onde se situa o dilema dos prisioneiros - existem amplos espaços para a análise da evolução da cooperação envolvendo, por exemplo, empresas concorrentes, localizadas em uma mesma localidade ou região. Na teoria voltada para o poder de mercado seria possível analisar o impacto das relações diferenciadas de parceria entre uma empresa e seus fornecedores, no que diz respeito às condições competitivas e ao posicionamento da empresa no mercado. Da perspectiva da teoria dos custos de transação podem ser estudadas parcerias no contexto de uma cadeia de suprimentos, enfocando-se fatores como a natureza mais ou menos repetitiva das transações, a especificidade dos ativos envolvidos, as incertezas em relação ao futuro. $\mathrm{O}$ recurso à teoria das redes sociais permitiria estudar, por exemplo, os condicionantes sociais existentes nos processos de realização de parceria e alianças estratégicas que envolvem empresas ou grupos empresariais. A teoria baseada em recursos tornaria possível abordar as relações de parceria como um tipo particular de recurso estratégico, capaz de desencadear a criação de novos recursos e capacidades, fundamental para o sucesso das empresas envolvidas. No contexto das teorias do aprendizado, a análise poderia enfocar as consequências de certos tipos de parcerias, em particular as que pressupõem compartilhamento e transferência de conhecimentos entre empresas distintas, na competitividade empresarial.

Na confluência desse rico conjunto de proposições e análises abrem-se interessantes vias de investigações, tanto de natureza teórica, quanto empírica. Apenas, a título de exemplo, destaca-se, no campo dos ensaios teóricos, a possibilidade de se enfocar, em profundidade, uma perspectiva teórica de cada vez. Devido a limitações de espaço, a análise aqui realizada sobre cada perspectiva ficou bastante sucinta. No entanto, cada uma delas é detentora de um conjunto também amplo de contribuições. Destaca-se, na dimensão empírica, a possibilidade de realização de análises comparadas cuidadosas, capazes de testar, em diferentes contextos empresariais, o grau de aplicabilidade prática de fundamentos presentes em distintas abordagens teóricas. Salienta-se que as observações sobre eventuais compatibilidades - ou incompatibilidades - teóricas presentes no interior do conjunto pesquisado se mostram particularmente importantes no atual estágio de evolução de pesquisas na área. O que se observa, em muitos dos estudos correntes, é uma tendência em direção à associação ou combinação de diferentes bases teóricas. Para concluir, espera-se que as reflexões aqui realizadas possam ajudar a criar uma visão mais abrangente, integrada e clara do universo de possibilidades presentes nesse fértil campo de conhecimentos, em plena construção. Espera-se, também, que possam desencadear um debate rico e frutífero.

\section{AGRADECIMENTOS}

Os autores agradecem as contribuições do Prof. Sérgio Fernando Loureiro Rezende ao presente artigo.

\section{REFERÊNCIAS BIBLIOGRÁFICAS}

Ambrosini, V., \& Bowman, C. (2009). What are dynamic capabilities and are they a useful construct in strategic management? International Journal of Management Reviews, 11(1), 29-49. 
Andrade, J. C. S., \& Dias, C. C. (2002, setembro). Alcances e limites da teoria dos jogos para a análise de situações de interdependência estratégia entre atores organizacionais. Anais do Encontro Nacional da Associação Nacional de Pós-Graduação e Pesquisa em Administração, Salvador, BA, Brasil, 26.

Arbage, A. P., \& Balestrin, A. (2007). A perspectiva dos custos de transação na formação de redes de cooperação. RAE Eletrônica, 6(1). http://www.scielo.br/pdf/raeel/v6n1/a08v6n1.pdf

Axelrod, R. (1984). The evolution of cooperation. New York: Basic Books.

Axelrod, R. (2001, July). Theoretical foundations of partnership for economic development. World Bank Conference on Evaluation and Development - The Partnership Dimension. Washington, DC.

Barney, J. B. (2002). Gaining and sustaining competitive advantages. New Jersey: Addison-Wesley Publishing Company Inc.

Begnis, H. S. M., Pedrozo, E. A., \& Estivalete, V. F. B. (2008). Cooperação enquanto diferentes perspectivas teóricas. Revista de Ciências da Administração, 10(21), 97-121.

Bowersox, D. J. (1998). Os benefícios estratégicos das alianças logísticas. Porter, M. E. \& Montgomery, C. A. (Eds.), Estratégia: a busca da vantagem competitiva (pp. 331-348). Rio de Janeiro: Harvard Business Review Book.

Bradach, J. L., \& Eccles, R. G. (1989). Markets versus hierarchies: from ideal types to plural forms. Annual Review of Sociology, 15, 97-118.

Brandenburguer A., \& Nalebuff, B. J. (1996). The right game: use game theory to shape strategy, Harvard Business Review, 73(4), 57-81.

Brandenburguer, A. M., \& Nalebuff, B. J. (1997). Co-opetition. Reino Unido: Harper Collins.

Burt, S. R. (1992). The social structure of competition. In N. Nohria \& R. G. Eccles (Eds.), Networks and organizations: structure, form and action (pp. 57-91). Massachusetts: Harvard Business School.

Child, J., Faulkner, D., \& Tallman, S. (2005). Cooperative strategy: managing alliances network and joint venture. New York: Oxford University Press.

Coase, R. H. (1937). The nature of firm. Economica, 4(16), 386-405.

Cohen, K. J., \& Cybert, R. M. (1965). Theory of the firm: resources allocation in a market economy. New Jersey: Prentice-Hall.

Combs, J. G., \& Ketchen, D. J., Jr. (1999). Explaining interfirm cooperation and performance: toward a reconciliation of predictions from the resources-based view and organizational economics. Strategic Management Journal, 20(9), 867- 888.

Contractor, F. J., \& Lorange, P. (1988). Why should firms cooperate? The strategic and economic basis for cooperative venture. In F. J. Contractor, P. Lorange (Eds.), Cooperative strategy in international business. New York: Lexington Book.

Costa, L. S. V. de (2005, setembro). Por que, com quem, como, quando, até quando? Estratégias colaborativas: a quantas anda essa "colcha de retalhos". Anais do Encontro Nacional da Associação Nacional de Pós-Graduação e Pesquisa em Administração, Brasília, DF, Brasil, 29.

Cross, R., Borgatti, S. P., \& Parker, A. (2002). Making invisible work visible: using social network analysis to support strategic collaboration. California Management Review, 44(2), 25-46. 
Dixit, A., \& Nalebuff, B. (1993). Thinking strategically: the competitive edge in business, politics and everyday life. Londres: W W Norton.

Dixit, A., \& Nalebuff, B. (2008). The art of strategy: a game theorist's guide to success in business and life. Londres: $\mathrm{W} \mathrm{W}$ Norton.

Eiriz, V. (2001). Proposta de tipologia sobre alianças estratégicas. Revista de Administração Contemporânea, 5(2), 65-90.

Elfring, T., \& Volberda, H. W. (2001). Schools of thought in strategic management: fragmentation, integration or synthesis. In T. Elfring \& H. W. Volberda (Eds.), Rethinking strategy (pp 2-25). London: Sage Publications.

Franco, M. J. B. (2007). Tipologia de processos de cooperação empresarial: uma investigação empírica sobre o caso português. Revista de Administração Contemporânea, 11(3), 149-176.

Gambson, W. A. (1961). A theory of coalition formation. American Sociological Review, 26(3), 373382.

Granovetter, M. (1973). The strength of weak ties. American Journal of Sociology, 78(6), 1360-1380.

Granovetter, M. (1985). Economic action and social structure: the problem of embeddedness. American Journal of Sociology, 91(3), 481-510.

Granovetter, M., \& McGuirre, P. (1998). The making of an industry: electricity in the United States. M. Callon (Ed.), The law of marketing (pp. 147-173). Oxford: Blackwell.

Gulati, R., Nohria, N., \& Zaheer, A. (2000). Strategic networks. Strategic management Journal, 21(3), 203-215.

Hamel, G. (1991). Competition for competence and inter-partner learning within international strategic alliances. Strategic Management Journal, 12(S1), 83-103.

Hamel, G., Doz, Y. L., \& Prahalad, C. K. (1989). Collaborate with your competitors and win. Harvard Business Review, 67(1), 133-139.

Hoskisson, R. E., Hitt, M. A., \& Wan, W. P (1999). Theory and research in strategic management: Swings of a pendulum. Journal of Management, 25(3), 417-456.

Houaiss, A., \& Vilar, M. S. de (2001). Dicionário Houaiss da Língua Portuguesa. Rio de Janeiro: Editora Objetiva.

Inkpen, A. (2006). Criando conhecimento por meio da colaboração. In J. Mintzberg, J. Lampel, J. B. Quinn, \& S. Ghoshal (Eds.), O processo da estratégia: conceitos, contextos e casos selecionados (Cap. 10, pp. 229-233). São Paulo: Bookman.

Itami, H., \& Roehl, T. (1987). Mobilizing invisible assets. Cambridge, MA: Harvard University Press.

Kale, P., Singh, H., \& Perlmutter, H. (2000). Learning and protection of property assets in strategic alliances: building relational capital. Strategic Management Journal, 21(3), 217-237.

Kanter, R. M. (1990). When giants learn cooperative strategies. Planning Review, 18(1), 15-22.

King, A. (2007). Cooperation between corporations and environmental groups: a transaction cost perspective. Academy of Management Review, 32(3), 889-900.

Kogut, B., \& Zander, U. (1992). Knowledge of the firm, combinative capabilities, and the replication of technology. Organization Science, 3(3), 383-397. 
Koza, M. P., \& Lewin, A. Y. (1998). The co-evolution of strategic alliances. Organization Science, 9(3) 255-264.

Larsson, R., Bentssson, L., Henriksson, K., \& Sparks, J. (1998). The inter-organizational learning dilemma: collective knowledge development in strategic alliances. Organizational Science, 9(3), 285-305.

Lastres, H. M. M., \& Ferraz, J. C. (1999). Economia da informação, do conhecimento e do aprendizado. In H. M. M. Lastres \& S. Albagli (Orgs.), Informação e globalização na era do conhecimento (pp. 27-57). Rio de Janeiro: Campos.

Lockett, A., Thompson, S., \& Morgenstern, U. (2009). The development of the resource-based view of the firm: a critical appraisal. International Journal of Management Reviews, 11(1), 9-28.

Lowendahl, B., \& Revang, O. (1998). Challenges to existing strategy theory in a postindustrial society. Strategic Management Journal, 19(8), 755-773.

Mahoney, J. T., \& MacGahan, A. M. (2007). The field of strategic management within the evolving science of strategic organization. Strategic Organization, 5(1), 79-99.

Malerba, F. (2005, September). Industrial dynamic and innovation: progress and challenges. Conference of European Association for Research in Industrial Economics, Porto, Portugal, 32.

Mascarenhas, B. (1989). Strategic group dynamics. Strategic Management Journal, 32(2), 333-352

Mellahi, K., \& Sminia, H. (2009). Guest editors' introduction: the frontiers of strategic management research. International Journal of Management Review, 11(1), 1-7.

Mintzberg, H. J. L. (2006). Um guia para posicionamento estratégico. In H. J. Mintzberg, J. Lampel, J. B. Quinn, \& S. Ghoshal (Eds.), O processo da estratégia: conceitos, contextos e casos selecionados (pp. 122-128). São Paulo: Bookman.

Mintzberg, H. J. L., Ahlstrand, B., \& Lampel, J. (2000). Safari da estratégia: um roteiro pela selva do planejamento estratégico. Porto Alegre: Bookman.

Newman, H. (1978). Strategic groups and the structure-performance relationship. Review of Economics and Statistics, 60(3), 417-427.

Nonaka, I. (1994). A dinamic theory of organizational knowledge creation. Organization Science, 5(1), 14-37.

Nonaka, I., \& Takeuchi, H. (1997). Criação de conhecimento na empresa. Como as empresas japonesas geram a dinâmica da inovação. São Paulo: Campus.

Osborn, R. N., \& Hagedoorn, J. (1997). The institutionalization and evolutionary dynamic of inter organization alliances and networks. Academy of Management Journal, 40(2), 261- 287.

Parkhe, A. (1993). Strategic alliance structuring: a game theoretic and transactional cost examination of interfirm cooperation. Academy of Management Journal, 36(4), 794-829.

Penrose, E. T. (1997). The theory of the growth of the firm. In N. J. Foss (Ed.), Resources, firms and strategies? A reader in the resource-based perspective (pp. 27-39). New York: Oxford University Press.

Peteraf, M. A. (1997). The cornerstones of competitive advantage: a resource-based view. In N. J. Foss (Ed.), Resources, firms and strategies? A reader in the resource-based perspective (pp. 187-203). New York: Oxford University Press. 
Pfeffer, J., \& Nowak, P. (1976). Joint ventures and interorganizational interdependence. Administrative Science Quarterly, 21(3), 398-418.

Polanyi, M. (1958). Personal knowledge. Towards a post critical philosophy. London: Routledge.

Polanyi, M. (1998). Personal knowledge. Towards a post critical philosophy. London: Routledge.

Porter, M. (1980). Competitive strategy: techniques for analyzing industry and competitors. New York: Free Press.

Porter, M. E. (1985). Competitive advantage. New York: Free Press.

Porter, M. E. (1990). The competitive advantages of nations. Londres: Macmillan.

Porter, M. E. (1999). Cluster e competitividade. HSM Management, 3(15), 15-25.

Porter, M. E. (2003). The economic performance of regions. Regional Studies, 37(6), 549-578.

Prahalad, C., K., \& Hamel, G. (1997). The core competence of the corporation. In N. J. Foss (Ed.), Resources, firms and strategies? A reader in the resource-based perspective (pp. 235-256). New York: Oxford University Press.

Preece, S. B. (2006). Por que criar alianças? In J. Mintzberg, J. Lampel, J. B. Quinn, \& S. Ghoshal (Eds.), O processo da estratégia: conceitos, contextos e casos selecionados (pp. 225-228). São Paulo: Bookman.

Quinn, J. B. (2006). Estratégias para mudanças. In H. Mintzberg, B. Ahlstrand, \& J. Lampel (Orgs.), O processo da estratégia (pp. 29-33). Porto Alegre: Bookman.

Simon, H. A. (1965). Comportamento administrativo: estudo dos processos decisórios nas organizações administrativas. Rio de Janeiro: Aliança para o Progresso.

Teece, D. J. (1997). Economies of scope and scope of the enterprise. In N. J. Foss (Ed.), Resources, firms and strategies? A reader in the resource-based perspective (pp. 103-116). New York: Oxford University Press.

Thompson, J. D. (1967). Organizations in action: social science bases of administrative theory. New York: McGraw-Hill.

Vale, G. M. V. (2007) Territórios vitoriosos: o papel das redes organizacionais. Rio de Janeiro: Garamond.

Vale, G. M. V., Amâncio, R., \& Lima, J. B. (2006). A criação e gestão de redes na estratégia competitiva de empresas e regiões. Revista de Administração, 41(2), 136-146.

Volberda, H. W. (2004). Crise em estratégia: fragmentação, integração ou síntese. Revista de Administração de Empresas, 44(4), 359-374.

Wagner, H. M. (1958). Advances in game theory. The American Economic Review, 48(3), 368-387.

Wernerfelt, B. (1997). Prefácio. In N. J. Foss (Ed.), Resources, firms and strategies? A reader in the resource-based perspective (pp xvii-xvii). New York: Oxford University Press.

Williamson, O. E. (1975). Markets and hierarchies: analysis and antitrust implications. New York: Free Press.

Williamson, O. E. (2005). The economics of governance. The American Economic Review, 95(2), 1-18. 